\title{
Management of Mendelian Traits in Breeding Programs by Gene Editing: A Simulation Study
}

John B. Cole ${ }^{1 *}$

${ }^{1}$ Animal Genomics and Improvement Laboratory, Agricultural Research Service, USDA, Beltsville, MD, USA

*Corresponding author

Email addresses:

JBC: John.Cole@ars.usda.gov 


\section{Abstract}

\section{Background}

3 Genotypes based on high-density single nucleotide polymorphisms have recently been used to

4 identify a number of novel recessive mutations that adversely affect fertility in dairy cattle as

5 well as to track conditions such as polledness. The use of sequential mate allocation strategies

6 that account for increases in genomic inbreeding and the economic impact of affected matings

7 may result in faster allele frequency changes than strategies that do not consider inbreeding and

8 monetary losses. However, the effect of gene editing on selection programs also should be

9 considered because gene editing has the potential to dramatically change allele frequencies in

10 livestock populations.

\section{Methods}

12 A simulation program developed to evaluate dairy cattle breeding schemes was extended to

13 include the use of clustered regularly interspaced short palindromic repeat (CRISPR),

14 transcription activator-like effector nuclease (TALEN), and zinc finger nuclease (ZFN)

15 technologies for gene editing. A hypothetical technology with a perfect success rate was used to

16 establish an upper limit on attainable progress, and a scenario with no editing served as a

17 baseline for comparison.

\section{$18 \quad$ Results}

19 The technologies differed in the rate of success of gene editing as well as the success rate of

20 embryo transfer based on literature estimates. The number of edited alleles was assumed to have

21 no effect on success rate. The two scenarios evaluated considered only the horned locus or 12

22 recessive alleles that currently are segregating in the U.S. Holstein population. The top 1, 5, or 
$2310 \%$ of bulls were edited each generation, and either no cows or the top $1 \%$ of cows were edited.

24 Inefficient editing technologies produced less cumulative genetic gain and lower inbreeding than

25 efficient ones. Gene editing was very effective at reducing the frequency of the horned haplotype

26 (increasing the frequency of polled animals in the population), and allele frequencies of the 12

27 recessives segregating in the U.S. Holstein population decreased faster with editing than without.

\section{Conclusions}

29 Gene editing can be an effective tool for reducing the rate of harmful alleles in a dairy cattle

30 population even if only a small proportion of elite animals are modified.

\section{$31 \quad$ Keywords}

32 allele frequency, gene editing, recessive disorders

\section{Background}

34 The widespread adoption and corresponding reduction in the cost of high-density single

35 nucleotide polymorphism (SNP) genotyping has enabled the detection of many new recessives

36 that have deleterious effects on fertility in several breeds of dairy cattle $[1,2,3]$, and whole

37 genome sequencing allows detecting additional fertility defects [4]. Many of these new

38 recessives were not previously detected by test matings because they cause embryonic losses in

39 early gestation that could not be distinguished from failed breedings. Annual losses to U.S. dairy

40 farmers from decreased fertility and increased perinatal mortality due to known recessive defects

41 are estimated to be at least $\$ 10$ million $(€ 9,370,754)$ [3]. Mate allocation tools do not always

42 consider carrier status when bull and cow pairs are assigned, and few make use of DNA marker

43 or haplotype information. Avoiding carrier-to-carrier matings is easy when only a few recessives 
44 are segregating in a population but is considerably more difficult when many defects are

45 segregating.

46 Cole [5] recently extended a simple method for controlling the rate of increase in genomic

47 inbreeding proposed by Pryce et al. [6] to account for economic losses attributable to recessive

48 defects. In the original method, parent averages (PAs) for matings that produced inbred offspring

49 were penalized, and the bull that produced the highest PA after the inbreeding adjustment was

50 selected in a sequential manner. The number of matings permitted for each bull was constrained

51 to prevent one bull with high genetic merit from being mated to all cows. Cole [5] modified this

52 approach to include an additional term that penalized carrier-to-carrier matings that may produce

53 affected embryos and showed that the additional penalty decreased minor allele frequency

54 (MAF) faster than other methods. However, many generations of selection were still needed to

55 eliminate recessives from the population, and some defects remained in the population at low

56 frequency.

57 A number of tools are now available for editing eukaryotic genomes, including clustered

58 regularly interspaced short palindromic repeats (CRISPR), transcription activator-like effector

59 nucleases (TALEN), and zinc finger nucleases (ZFN) [7,8]. Treating simple recessive disorders

60 by using gene editing is of great interest (e.g., [9]), and CRISPR has been used to generate pigs

61 that are resistant to porcine reproductive and respiratory syndrome [10]. Gene editing also has

62 been used to produce desirable phenotypes (e.g., polled cattle [11]). A recent series of simulation

63 studies showed that gene editing also has the potential to improve rates of genetic gain for

64 quantitative traits $[12,13]$. Gene editing may be an effective means of reducing the frequency of

65 genetic disorders in livestock populations or eliminating those disorders altogether. 
66 The objective of this research was to determine rates of allele frequency change and quantify

67 differences in cumulative genetic gain through simulation for several genome editing

68 technologies while considering varying numbers of recessives and different proportions of bulls

69 and cows to be edited.

\section{Methods}

\section{Simulation}

72 The simulation software of Cole [14] was modified to include four different gene editing

73 technologies and used to examine several scenarios for the use of gene editing in a dairy cattle

74 population. With the exception of the gene editing methodology, the simulation procedures were

75 identical to those described in detail by Cole [5]. Thirteen software parameters were used in the

76 simulations (Table 1).

\section{Table 1 Simulation parameters}

\begin{tabular}{|c|c|c|}
\hline $\begin{array}{l}\text { Software } \\
\text { parameter }\end{array}$ & Definition & Value \\
\hline base_bulls & Number of bulls in the base population & 350 \\
\hline base_cows & Number of cows in the base population & 35,000 \\
\hline service_bulls & Number of bulls in the sire portfolio used by each herd & 50 \\
\hline base_herds & Number of pseudo-herds used in the simulation & 200 \\
\hline max_bulls & $\begin{array}{l}\text { Maximum number of bulls available for use as service sires in each } \\
\text { generation }\end{array}$ & 500 \\
\hline max_cows & Maximum number of cows in the population in each generation & 100,000 \\
\hline generations & Number of generations simulated & 20 \\
\hline max_mating & Maximum number of matings each service sire is permitted each year & 5000 \\
\hline debug & Show or hide debugging messages & True \\
\hline history_freq & Frequency with which history files are saved to disk & End \\
\hline rng_seed ${ }^{2}$ & Value used to seed the random number generator & Time + PID \\
\hline edit_prop & Proportions of bulls and cows edited in different scenarios & $\begin{array}{l}0 \%, 1 \%, 10 \% \text { (bulls) } \\
0 \%, 1 \%(\text { cows })\end{array}$ \\
\hline edit_type ${ }^{3}$ & Technologies used for gene editing & $\mathrm{C}, \mathrm{P}, \mathrm{T}, \mathrm{Z}$ \\
\hline
\end{tabular}

Time system clock time when the simulation is submitted, PID process identification reported by the operating system, $C$ clustered regularly interspaced short palindromic repeats, $T$ transcription activator-like effector nuclease, $P$ hypothetical technology with perfect success rate, $Z$ zinc finger nuclease 
78 The modified Pryce scheme accounting for recessive alleles described by Cole [5] was used to

79 allocate bulls to cows in all scenarios. The selection criterion was the 2014 revision of the

80 lifetime net merit (NM\$) genetic-economic index used in the United States [15]. For each herd,

$8120 \%$ of the bulls were randomly selected from a list of live bulls, and the top 50 bulls from that

82 group were selected for use as herd sires based on true breeding value (TBV). This produced

83 different sire portfolios for each herd and is similar to the approach of Pryce et al. [6].

84 As in Cole [5], a matrix of PAs $\left(\mathbf{B}^{\prime}\right)$ was constructed with rows corresponding to bulls and

85 columns corresponding to cows as

86

$$
B_{i j}^{\prime}=0.5\left(T B V_{i}+T B V_{j}\right)-\lambda F_{i j}-\sum_{r=1}^{n_{r}} P(a a)_{r} \times v_{r}
$$

87 where $B_{i j}^{\prime}$ is the PA for offspring of bull $i$ and cow $j, T B V_{i}$ is the TBV NM\$ for bull $i, T B V_{j}$ is

88 the TBV NM $\$$ for cow $j, \lambda$ is the inbreeding depression in dollars associated with a $1 \%$ increase

89 in inbreeding, $F_{i j}$ is the pedigree coefficient of inbreeding of the calf resulting from mating bull $i$

90 to cow $j, n_{r}$ is the number of recessive alleles in a scenario, $P(a a)_{r}$ is the probability of

91 producing an affected calf for recessive locus $r$, and $v_{r}$ is the economic value of locus $r$. The

92 regression coefficient of NM\$ on inbreeding $(\lambda)$ was computed as the weighted average of the

93 December 2014 effects of inbreeding on the traits in the index as done by Cole [5]; the weights

94 correspond to those assigned to each trait in the NM\$ index and resulted in a $\lambda$ of $\$ 25$. The $P(a a)$

95 equals 0.25 for a mating of two carriers, 0.5 for a mating of an affected animal with a carrier, or

961 for a mating of two affected animals. Thirteen recessive loci were used in the simulations

97 (Table 2). 
Table 2 Properties of the recessive loci included in each simulated scenario

\begin{tabular}{|c|c|c|c|c|c|}
\hline Scenario & $\mathbf{N}^{\mathbf{a}}$ & Frequency & Value $(\$)^{\mathbf{b}}$ & Name & Lethal \\
\hline \multirow[t]{12}{*}{ All recessive loci } & 12 & 0.0276 & 150 & Brachyspina & Yes \\
\hline & & 0.0192 & 40 & HH1 & Yes \\
\hline & & 0.0166 & 40 & HH2 & Yes \\
\hline & & 0.0295 & 40 & HH3 & Yes \\
\hline & & 0.0037 & 40 & $\mathrm{HH} 4$ & Yes \\
\hline & & 0.0222 & 40 & HH5 & Yes \\
\hline & & 0.0025 & 150 & BLAD & Yes \\
\hline & & 0.0137 & 70 & CVM & Yes \\
\hline & & 0.0001 & 40 & DUMPS & Yes \\
\hline & & 0.0007 & 150 & Mulefoot & Yes \\
\hline & & 0.9929 & 40 & Horned & No \\
\hline & & 0.0542 & -20 & Red coat color & No \\
\hline Horned locus & 1 & 0.9929 & 40 & Horned & No \\
\hline
\end{tabular}

$H H 1, H H 2, H H 3, H H 4, H H 5$ Holstein fertility haplotypes 1,2,3,4,5, respectively, $B L A D$ bovine leukocyte adhesion deficiency, CVM complex vertebral malformation, DUMPS deficiency of uridine monophosphate synthase ${ }^{a}$ Number of recessive loci in the scenario.

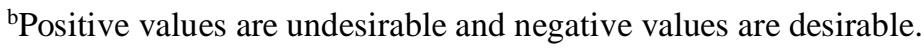

98 After $\mathbf{B}^{\prime}$ was constructed, a matrix of matings (M) was used to allocate bulls to cows. An

99 element $\left(M_{i j}\right)$ was set to 1 if the corresponding $B_{i j}^{\prime}$ value was the greatest value in column $j$ (that

100 bull produces the largest PA of any bull available for mating to that cow); all the other elements

101 of that column were set to 0 . If the sum of the elements of row $i$ was less than the maximum

102 number of permitted matings for that bull, then the mating was allocated. Otherwise, the bull

103 with the next-highest $B_{i j}^{\prime}$ value in the column was selected. This procedure was repeated until

104 each column had only one element equal to 1.

105 Gene editing

106 In the simulation model, gene editing occurred when an embryo was created. The following six

107 steps were used and repeated for each locus to be edited:

108 Step 1: Sort candidates on TBV in descending order.

109 Step 2: Select animals to be edited based on the user-specified proportion. 
110 Step 3: Edit $A a$ and $a a$ genotypes to $A A$ genotypes (all edited animals are assumed to be

111 homozygous).

112 Step 4: Draw a uniform random variate and compare with the editing failure rate of the method

113 to determine if the editing procedure was successful. This check was made to determine if the

114 recessive $(a)$ alleles were successfully changed to dominant $(A)$ alleles in the embryo.

115 Step 5: Draw a uniform random variate and compare with the embryonic death rate of the

116 method to determine if the embryo transfer (ET) procedure was successful. This check was made

117 to determine if the edited embryo survived the ET procedure and resulted in a live calf.

118 Step 6: Update the animal record.

119 The overall success rate was the product of the editing success and embryonic death rates (Steps

1204 and 5). Figure 1 shows a flowchart describing the process in detail. The editing failure rate can

121 be set to 0 to represent a scenario in which only embryos that were successfully edited are

122 transferred to recipients. A scenario in which many embryos are produced so that survival of

123 some is guaranteed can be simulated by setting the embryonic death rate to 0.

\section{Please place Fig. 1 around here}

124 Three laboratory approaches to gene editing (CRISPR, TALEN, and ZFN) were supported as

125 well as a fourth method that assumes that editing always is successful. The CRISPR, TALEN,

126 and ZFN methods differed in their editing success and embryonic death rates [7,8] (Table 3).

127 Bulls and cows could be edited at different rates (e.g., 10\% of bulls and 1\% of cows). Any

128 combination of loci could be edited, and the number of edited loci was not restricted. A scenario

129 in which no genes were edited, which reflects current practice, was used as the baseline against 
130 which the various editing scenarios were compared. A schematic of the simulated scenarios is in

131 Figure 2.

132 Table 3 Gene editing failure and embryonic death rates and trials needed for a live calf

\begin{tabular}{|c|c|c|c|c|c|c|}
\hline \multirow{2}{*}{$\begin{array}{l}\text { Technolog } \\
\text { y }\end{array}$} & \multirow{2}{*}{$\begin{array}{l}\text { Editing failure } \\
\text { rate }\end{array}$} & \multirow{2}{*}{$\begin{array}{l}\text { Embryonic death } \\
\text { rate }\end{array}$} & \multirow{2}{*}{$\begin{array}{l}\text { Success } \\
\text { probability }^{\mathrm{a}}\end{array}$} & \multicolumn{3}{|l|}{ Trials (no.) } \\
\hline & & & & $\begin{array}{l}\text { Successful } \\
\text { edit }\end{array}$ & Successful ET & Live calf \\
\hline CRISPR & 0.37 & 0.79 & 0.71 & 5 & 20 & 100 \\
\hline TALEN & 0.79 & 0.88 & 0.30 & 20 & 37 & 740 \\
\hline Perfect & 0.00 & 0.00 & 1.00 & 1 & 1 & 1 \\
\hline ZFN & 0.89 & 0.92 & 0.18 & 40 & 56 & 2240 \\
\hline
\end{tabular}

CRISPR clustered regularly interspaced short palindromic repeats, TALEN transcription activator-like effector nuclease, Perfect hypothetical technology with a perfect success rate, ZFN zinc finger nuclease, ET embryo transfer. ${ }^{a}$ Calculated as $1-$ (editing failure rate $\times$ embryonic death rate).

\section{Please place Fig. 2 around here}

\section{Analysis}

$134 \quad$ Trials required

135 The number of trials required to produce a live, gene-edited calf was determined for each of the

136 four editing technologies (Table 3) by computing the number of draws needed from a geometric

137 distribution to have a $99 \%$ probability of obtaining a success using the editing failure and

138 embryonic death rates as the probability of success. The total number of trials was the product of

139 the number of trials required for a successful edit and the number of trials needed for a

140 successful ET. Producing a calf of the desired sex was assumed to be possible through the use of

141 sexed semen, selection among the embryos in a flush, or other assisted reproductive technology.

143 The results for each scenario were averaged over 10 replicates. Observed changes in allele

144 frequency were compared against expectations, and expected allele frequencies in each

145 generation for lethal defects were calculated as in [16]: 


$$
p_{t}=\frac{p_{t-1}^{2}+p_{t-1}\left(q_{t-1}\right)}{2 p_{t-1}^{2}+p_{t-1}\left(q_{t-1}\right)}
$$

147

$$
q_{t}=\frac{p_{t-1}\left(q_{t-1}\right)}{2 p_{t-1}^{2}+p_{t-1}\left(q_{t-1}\right)},
$$

148

149

150 151 alleles were calculated using Hardy-Weinberg proportions [17]:

152

153

154

155

156

157

158

159

160

161

$$
\begin{aligned}
& p_{t}=p_{t-1}^{2}+p_{t-1}\left(q_{t-1}\right) \\
& q_{t}=q_{t-1}^{2}+p_{t-1}\left(q_{t-1}\right)
\end{aligned}
$$

\section{Rate of allele frequency change}

$$
y_{t}=b_{0}+b_{1} g_{t}+b_{2} g_{t}^{2}+e_{t}
$$
generation number at time $t$, and $e_{t}$ is the random residual error.

where $p_{t}$ is the frequency of the major allele at time $t, q_{t}$ is the MAF at time $t$, and $t$ ranges from 1 to 20 years. The MAF at time 0 was used in each scenario for each recessive locus (Table 2), and the major allele frequency was calculated as 1 - MAF. Expected frequencies for non-lethal

For each recessive locus in each scenario, observed allele frequencies were regressed on birth year using the Python module Statsmodels version 0.6.1 ([18,19]) using the model:

where $y_{t}$ is the frequency of a recessive locus at time $t, b_{0}$ is the intercept, $b_{1}$ is the regression coefficient associated with the linear effect of time, $g_{t}$ is the generation number at time $t, b_{2}$ is the regression coefficient associated with the quadratic effect of time, $g_{t}^{2}$ is the square of the 
162

163

164

165

166

167

168

169

170

171

172

173

174

175

176

177 production were publicly available.

\section{Trials required for successful procedures}

179 The numbers of trials required to ensure a 99\% chance of successfully editing embryos (Step 4)

180 and of getting a live calf on the ground following ET (Step 5) are in Table 3. Of the existing

181 technologies, CRISPR was the most efficient by a factor of $\sim$, requiring only 100 trials to

182 produce a live calf. ZFN was only a quarter as efficient, requiring 2240 trials to produce a live

\section{Visualization}

Plots of actual versus expected allele frequencies and the change in carrier proportions over time were constructed using matplotlib version 1.5.1 [20,21]. Changes in observed allele frequencies over time were plotted using Seaborn version 0.5.1 [22].

\section{Results and discussion}

\section{Scenarios}

Two scenarios are discussed: $1 \%$ of bulls and $0 \%$ of cows edited, and $10 \%$ of bulls and $1 \%$ of cows edited. These scenarios represented the two extremes (least versus most editing), and the results from the other scenarios were intermediate to these results. When selection is based on TBV and not carrier status, more efficient editing procedures generally produce greater responses. Recent research has shown that biopsies of bovine embryos, such as might be used for genotyping, do not affect pregnancy rate [23]; therefore, success rates might be improved through more rigorous ET protocols for edited embryos even when editing technologies differ. Although the cost of producing gene-edited animals decreases as the technology becomes more efficient, this study did not examine those differences because no data on actual costs of calf. Although determining the actual cost of producing a gene-edited calf is difficult, $\$ 10,000$ 
184 per animal seems reasonable [24]. Production costs would then range from \$1 million (CRISPR)

185

186

187

188

189

190

191 required if many loci are edited in the same embryo.

192 An additional assumption was that only one embryo was edited per mating (only a single trial

193 was carried out). However, in practice, many embryos would be edited and transferred to ensure

194 the live birth of a calf of the desired sex. As discussed, such cases may be simulated by setting

195 the editing failure rate and the embryonic death rate to 0 . Therefore, the results of this study are

196 underestimates of allele frequency changes that might be observed in commercial production.

\section{Allele frequency changes}

\section{$198 \quad$ Recessive loci}

199 Only results for $\mathrm{HH} 3$ from the simulations that included all 12 Holstein recessives and for

200 horned are discussed. The other loci in the 12-recessive simulation had results similar to those

201 for HH3 (for lethals) and horned (the polled locus). These trends are broadly similar to the

202 results of Segelke et al. [26], who showed that MAFs decrease much faster when dams are

203 selected using an index based on six loci $(\mathrm{HH} 1, \mathrm{HH} 2, \mathrm{HH} 3, \mathrm{HH} 4, \mathrm{HH} 5$, and polled) rather than

204 on breeding values for fertility. 
$205 \quad H H 3$

206 The causal variant associated with HH3 is a non-synonymous mutation in the SMC2 (structural

207 maintenance of chromosomes 2) gene at 95,410,507 bp on bovine chromosome (BTA for Bos

208

209

210

211

212 trends exceeded expected trends (Fig. 4). Differences between methods were much greater than

213 differences between proportions of animals edited. This may be due, in part, to the failure model

214 used in the simulation: when an edit is unsuccessful, the animal's genotype at the edited locus is

215 not changed. Inefficient technologies will often fail to change heterozygous $(A a)$ genotypes to

216 homozygous dominant $(A A)$ genotypes, which reduces the rate at which allele frequencies

217 change. The addition of females did not have a notable effect on rates of allele frequency change.

218 This may be due to the absence from the simulation of advanced reproductive technologies used

219 to propagate elite genotypes (e.g., in vitro fertilization combined with ET for elite cow families
to produce flushes of embryos with high PAs). 
Table 4 Coefficients for regression of observed allele frequency on birth year and standard errors

\begin{tabular}{|c|c|c|c|c|c|c|c|c|c|}
\hline \multirow[t]{2}{*}{ Recessive } & \multirow[t]{2}{*}{ Technology } & \multicolumn{4}{|c|}{$1 \%$ bulls and $0 \%$ cows gene edited ${ }^{\mathrm{a}, \mathrm{b}}$} & \multicolumn{4}{|c|}{$10 \%$ bulls and $1 \%$ cows edited ${ }^{\mathrm{a}, \mathrm{b}}$} \\
\hline & & $\mathrm{b}_{\text {linear }}$ & $\mathrm{SE}_{\text {linear }}$ & $\mathrm{b}_{\text {quadratic }}$ & $\mathrm{SE}_{\text {quadratic }}$ & $\mathrm{b}_{\text {linear }}$ & $\mathrm{SE}_{\text {linear }}$ & $\mathrm{b}_{\text {quadratic }}$ & $\mathrm{SE}_{\text {quadratic }}$ \\
\hline \multirow{5}{*}{$\mathrm{HH} 3$} & No edits & $-0.0007 * *$ & 0.000 & $-2.28 E-05$ & $1.06 \mathrm{E}-05$ & 0.0003 & 0.000 & $-5.93 \mathrm{E}-05 * *$ & $8.64 \mathrm{E}-06$ \\
\hline & $\mathrm{ZFN}$ & $-0.0014 * *$ & 0.000 & $1.059 E-05$ & $1.3 \mathrm{E}-05$ & 0.0002 & 0.000 & $-4.86 \mathrm{E}-05^{* *}$ & $1.12 \mathrm{E}-05$ \\
\hline & TALEN & $-0.0026^{* *}$ & 0.000 & $8.43 \mathrm{E}-05^{* *}$ & $8.26 \mathrm{E}-06$ & $-0.0012 * *$ & 0.000 & $2.677 \mathrm{E}-05$ & $1.07 E-05$ \\
\hline & CRISPR & $-0.0048 * *$ & 0.000 & $0.0001 * *$ & $7.67 \mathrm{E}-06$ & $-0.0031 * *$ & 0.000 & $5.001 \mathrm{E}-05^{*}$ & $1.54 \mathrm{E}-05$ \\
\hline & Perfect & $-0.0050 * *$ & 0.000 & $0.0002 * *$ & $1.13 \mathrm{E}-05$ & $-0.0050 * *$ & 0.000 & $0.0002 * *$ & $8.75 \mathrm{E}-06$ \\
\hline \multirow[t]{5}{*}{ Horned } & No edits & $-0.0006^{* *}$ & 0.000 & $1.677 \mathrm{E}-05$ & $6.34 \mathrm{E}-06$ & $-0.0017 * *$ & 0.000 & $0.0001 * *$ & $1.89 \mathrm{E}-05$ \\
\hline & $\mathrm{ZFN}$ & $-0.0109 * *$ & 0.001 & -0.0002 & $3.66 \mathrm{E}-05$ & $-0.0123 * *$ & 0.001 & $-0.0004 * *$ & $6.65 \mathrm{E}-05$ \\
\hline & TALEN & $-0.0303^{* *}$ & 0.003 & $-3.098 \mathrm{E}-05$ & 0.000 & $-0.0338 * *$ & 0.003 & 0.0001 & 0.000 \\
\hline & CRISPR & $-0.0986^{* *}$ & 0.005 & $0.0022 * *$ & 0.000 & $-0.1070 * *$ & 0.006 & $0.0025^{* *}$ & 0.000 \\
\hline & Perfect & $-0.1428 * *$ & 0.006 & $0.0044 * *$ & 0.000 & $-0.1418 * *$ & 0.006 & $0.0044 * *$ & 0.000 \\
\hline
\end{tabular}

Regression was for five different editing technologies over 20 years in scenarios where either the top $1 \%$ of bulls and $0 \%$ cows were edited or the top $10 \%$ of bulls and top $1 \%$ of cows were edited.CRISPR clustered regularly interspaced short palindromic repeats, TALEN transcription activator-like effector nuclease, Perfect hypothetical technology with a perfect success rate, $Z F N$ zinc finger nuclease; $b$ regression coefficient; SE standard error ${ }^{\mathrm{a}} t$ test significance for the hypotheses that $\left|\mathrm{b}_{\text {linear }}\right|=0$ and $\left|\mathrm{b}_{\text {quadratic }}\right|=0: * P<0.01, * * P<0.001$; bold terms did not differ from 0.

${ }^{\mathrm{b}}$ The software used for analysis displays only three digits, $\mathrm{SE}<0.001$ were truncated to 0.000 , but actual values were not exactly 0 .

\section{Please place Fig. 3 around here}

\section{Please place Fig. 4 around here}

221 Rates of inbreeding did not differ between editing methods when only bulls and no cows were

222 edited (Fig. 5a). However, rates of inbreeding did differ when both bulls and cows were edited

223 (Fig. 5b) for CRISPR, TALEN, and ZFN. When the ET process fails, the embryo dies (Fig. 1),

224 which results in the loss of a calf with high-genetic-merit in the next generation because only

225 elite embryos are edited. If the process is inefficient and many embryos die, then animals are

226 used as sires that would otherwise not be selected. The reduction in inbreeding is greatest for the

227 least efficient method (ZFN), followed in order by TALEN and CRISPR. Editing methods with

228 high failure rates result in the selection of parents that would not otherwise have been selected,

229 which reduces within-family matings and inbreeding rates.

\section{Please place Fig. 5 around here}




\section{Horned}

231 The polled (hornless) state is dominant to the horned state. This discussion is focused on horned,

232 the recessive allele, to mirror the results and discussion for $\mathrm{HH} 3$ as well as findings of Cole [5].

233 Previous studies on breeding strategies for decreasing the frequency of the recessive (horned)

234 allele in dairy cattle (e.g., [5,28,29]) suggested that rates of change would be very slow, and a

235 number of authors have instead proposed selection directly on the polled locus or linked markers

236 (e.g., [30,31,32,33,34]). Long-term progress can be improved slightly by putting more weight on

237 favorable minor alleles in selection programs [35], but progress would be much faster using gene

238 edits for the favorable allele.

239 In this simulation, a single locus was assumed to control polledness, but in reality the polled

240 locus is more complex than $\mathrm{HH} 3$ and has at least two mutations on BTA1 that result in hornless

241 cattle [36,37]. All gene-editing methods resulted in significant rates of allele frequency change

242 (Table 4), with rates of change increasing with the efficiency of the technology (Fig. 6).

243 Regression coefficients were similar regardless of the proportion of bulls and cows edited. In

244 contrast to the results obtained for $\mathrm{HH} 3$, observed trends were greater than expected trends for

245 every editing technology (Fig. 7). Differences between methods were much greater than

246 differences between proportions of animals edited. Even the least-efficient editing technology

247 produced large reductions in the frequency of horned cattle, which is a notable improvement

248 over the results of Cole [5], who found no allele frequency change after including the economic

249 value of polledness in the selection criterion. Differences in rates of inbreeding for the horned

250 locus (not shown) were similar to those observed for $\mathrm{HH}$, again supporting that higher failure

251 rates will result in sampling more diverse pedigrees than would otherwise be the case. 


\section{Please place Fig. 6 around here \\ Please place Fig. 7 around here}

\section{Cumulative genetic gain}

253 Two sets of $t$ tests were conducted to evaluate cumulative genetic gain over the 30 years (10

254 rounds of burn-in and 20 rounds of selection) of the simulation. First, a $t$ test was used to

255 compare each gene editing technology within a scenario against no gene editing to determine if

256 different technologies produce different rates of gain. Then a set of $t$ tests was used to compare

257 gene editing technologies across scenarios to determine if the proportion of animals edited had

258 an effect on cumulative gain. Results differed slightly between the horned-only and 12-recessive

259 scenarios; however, the pattern of responses was the same, and only results for the 12-recessive

260 scenario are discussed.

261 The pattern for cumulative genetic gain was similar to that for rates of inbreeding. The Perfect

262 technology did not differ from no gene editing for either $1 \%$ bulls and no cows edited or $10 \%$ of

263 bulls and $1 \%$ of cows edited. However, CRISPR, TALEN, and ZFN all showed significantly

264 lower cumulative genetic gains $(P<0.01)$, with larger differences for less efficient technologies.

265 Similarly, the scenarios with higher rates of editing also had no differences for no gene editing

266 and the Perfect technology as well as significantly lower rates of gain for CRISPR, TALEN, and

267 ZFN $(P<0.01)$. As previously discussed, when many embryos die during ET, fewer elite

268 animals are available to become parents in the next generation. This resulted in lower rates of

269 genetic gain that were proportional to the ET failure rate over the course of the simulation.

\section{Scenario comparison}

271 For both editing scenarios (1\% of bulls and $0 \%$ of cows edited, and $10 \%$ of bulls and $1 \%$ of cows 
272 edited), the use of gene editing resulted in faster allele frequency changes; more efficient

273 technologies produced faster rates of change. A comparison of results for the horned locus from

274 the horned-only and 12-recessive scenarios (not shown) indicates that the number of loci edited

275 in a scenario had no effect on the rates of allele frequency change. This is expected because gene

276 edits are modelled as independent events, and few animals are carriers of more than one

277 recessive.

\section{Embryonic losses}

279 The proportion of embryos that died in each birth year because they were homozygous for lethal

280 conditions (Fig 8) also decreased rapidly when only $1 \%$ of bulls and no cows were edited using

281 CRISPR and TALEN. When the editing procedure is highly efficient, fewer affected embryos

282 are produced, even when the number of edited parents is few. The Perfect technology produced

283 rapid decreases in both scenarios as expected.

\section{Please place Fig. 8 around here}

284 These results contrast with those of Cole [5], who reported that the number of embryos that died

285 from recessive disorders was higher for scenarios with constrained inbreeding and penalized

286 carrier parents. Cole concluded that the goal of eliminating recessive alleles from the population

287 (fixing haplotypes in a homozygous state) conflicted with the goal of minimizing inbreeding

288 (avoidance of increases in homozygosity). However, if loci can be edited, then favourable alleles

289 can be introduced without affecting overall inbreeding in the population because the number of

290 known recessives is low compared to the size of the genome. These results also may reflect the

291 parameters used in the simulation. With a cow population of 100,000 and 5000 matings

292 permitted per year per bull, a cohort of only 20 bulls could breed every cow in the population. If 
293 the top $10 \%$ of bulls $(n=50)$ were edited, all cows could have been bred to gene-edited bulls and

294 no affected embryos produced.

\section{Avoidance of carrier bulls}

296 The proportion of bulls edited had only small effects on allele frequency changes, and the

297 proportion of cows edited had essentially no effect on allele frequency changes, possibly because

298 of the small proportion of cows edited. However, assuming higher editing rates is unrealistic

299 given current limitations of the technology. In the future, artificial-insemination firms may

300 simply refuse to purchase embryos or calves that are carriers of known genetic defects and forgo

301 very little (or no) genetic gain to eliminate recessives from the population rapidly. Cole et al. [3]

302 showed that genetic merit for NM\$ of Ayrshire and Jersey bulls that carry at least one known

303 recessive disorder does not differ from those free of known recessives and that Brown Swiss $(P=$

$3040.087)$ and Holstein $(P<0.001)$ carriers have lower average predicted transmitting abilities than

305 non-carriers. The proportion of genotyped Holstein bulls and cows born since 2000 that are

306 carriers of at least one known recessive was fairly constant between 2000 and 2010 but began to

307 decrease more quickly in 2011(Fig. 9), which is when haplotype tests were introduced for several

308 new genetic disorders [1]. Collectively, these results suggest that artificial-insemination firms

309 already avoid carrier bulls when purchasing embryos and young bulls. This approach is probably

310 the fastest and least expensive for eliminating harmful genetic defects from the population, but it

311 will not increase the frequency of desirable attributes (e.g., polledness).

\section{Please place Fig. 9 around here}

\section{Regulatory considerations}


313 Although some gene-edited products recently have reached the U.S. marketplace [38,39],

314 regulatory uncertainty remains a concern [40]. This was underscored by much of the discussion

315 at the 2016 Large Animal Genetic Engineering Summit [41], which focused largely on the use of

316 gene editing and other tools to produce large animal models of human disease (e.g., [42]) rather

317 than food animals because of the concerns surrounding consumer acceptance of gene-edited

318 animals in the food chain. Policymakers and regulators are being encouraged to exercise

319 oversight based on the product rather than the tool used to generate that product [43], but if (or

320 when) meat and milk from gene-edited animals will be offered for sale is not clear at present.

\section{Acceptance of gene editing}

322 Consumers and regulators may be more willing to support the use of gene editing for improving

323 animal welfare rather than simply for increasing productivity. For example, the process of

324 dehorning is traumatic to calves, unpleasant for farmers, and distasteful to consumers (e.g., [44]).

325 Previous studies [5,29] have shown that increasing the frequency of polled animals in the

326 Holstein population is difficult because the frequency of the dominant allele is very low

327 (0.0061). Carlson et al. [11] have successfully produced polled clones of horned animals using

328 gene editing with no detectable off-target effects, which shows that the technology could be used

329 to propagate desirable polled genotypes rapidly. Gene editing also has been used to produce

330 animals with increased resistance to disease [45], including porcine reproductive and respiratory

331 syndrome [10,46] and bovine tuberculosis [47]. Other candidates for gene editing include casein

332 variants that may have beneficial effects on human health [48], the slick locus that is involved in

333 adaptation to hot environments thermotolerance [49], and the DGAT1 gene which has favourable

334 effects on milk composition [50]. 
335 Many challenges are associated with genetically modified organisms, some technical and others

336 related to consumer attitudes towards the technology [51,52]. Although the technology has

337 improved dramatically in recent years, the general public remains concerned about genetically

338 modifying food crops and livestock. A recent meta-analysis of the literature on consumer

339 preferences suggests that U.S. respondents have a more favourable view of biotechnologically

340 modified food products than those from Europe, but that most consumers are concerned about

341 genetically modified animals [53]. Consumers that are generally opposed to the marketing of

342 genetically modified organisms may moderate those opinions in the presence of another benefit

343 (e.g., increased levels of omega-3 fatty acids in farmed salmon) [54]. Changing consumer

344 attitudes towards technologies may be possible, but the arguments need to focus on the benefits

345 rather than the technology [55]. Consumers may be more accepting of gene editing in food

346 animals if the technology focus is on animal health and welfare rather than productivity.

\section{Conclusions}

348 The efficiency of gene editing technologies has a greater effect on allele frequency change than

349 the proportion of animals in the population edited. Gene editing is a useful tool for increasing the

350 frequency of desirable characteristics that are at low frequency in current populations (e.g.,

351 polledness). Removing carriers of harmful recessives from the population may be more effective

352 than correcting them with gene editing. The use of gene editing to increase the frequency of

353 alleles that confer resistance to disease may be more acceptable to consumers than using the

354 technology to increase genetic merit for quantitative traits. Applications of gene editing in

355 livestock should focus on loci with large, beneficial impacts on animal health rather than on

356 recessive defects with low allele frequencies in the population, because the latter can better be

357 managed through mating programs. 


\section{$358 \quad$ Declarations}

\section{Ethics approval and consent to participate}

360 This study involved no animal experimentation and did not require any authorization from local

361 ethics committee.

\section{Consent for publication}

363 Not applicable.

\section{Availability of data and material}

365 The source code for the simulation and the Jupyter [56] notebooks used to analyze the data are

366 available on GitHub [14] under a Creative Commons CCO 1.0 Universal (public domain)

367 license.

\section{Competing interests}

369 The author declares that he has no competing interests. Mention of trade names or commercial

370 products in this article is solely for the purpose of providing specific information and does not

371 imply USDA recommendation or endorsement. USDA is an equal opportunity provider and

372 employer.

\section{$373 \quad$ Funding}

374 JBC was supported by appropriated project 8042-31000-101-00 (Improving Genetic Predictions

375 in Dairy Animals Using Phenotypic and Genomic Information) of the Agricultural Research

376 Service, USDA. 


\section{Authors' contributions}

378 Not applicable.

\section{Acknowledgements}

380 Suzanne Hubbard and Daniel Null (Animal Genomics and Improvement Laboratory,

381 Agricultural Research Service, USDA, Beltsville, MD) assisted with figures and technical

382 editing, and Kristen Parker Gaddis (Council on Dairy Cattle Breeding, Bowie, MD) and Paul

383 VanRaden (Animal Genomics and Improvement Laboratory, Agricultural Research Service,

384 USDA, Beltsville, MD) provided several insightful comments about the manuscript.

\section{References}

386 1. VanRaden PM, Olson KM, Null DJ, Hutchison JL. Harmful recessive effects on fertility

387 detected by absence of homozygous haplotypes. J Dairy Sci. 2011;94:6153-61.

388 2. Cole JB, VanRaden PM, Null DJ, Hutchison JL, Cooper TA, Hubbard SM. AIP Research

389 Report GENOMIC3 (09-13): Haplotype tests for recessive disorders that affect fertility and other

390 traits. In: Animal Improvement Program. Animal Genomics and Improvement Laboratory, ARS,

391 USDA. 2016. https://aipl.arsusda.gov/reference/recessive_haplotypes_ARR-G3.html. Accessed

$392 \quad 23$ Feb 2017.

393 3. Cole JB, Null DJ, VanRaden PM. Phenotypic and genetic effects of recessive haplotypes on

394 yield, longevity, and fertility. J Dairy Sci. 2016;99:7274-88.

395 4. Charlier C, Li W, Harland C, Littlejohn M, Coppieters W, Creagh F, et al. NGS-based

396 reverse genetic screen for common embryonic lethal mutations compromising fertility in

397 livestock. Genome Res. 2016;26:1-9. 
program. Genet Sel Evol. 2015;47:947.

400

6. Pryce JE, Hayes BJ, Goddard ME. 2012. Novel strategies to minimize progeny inbreeding

401 while maximizing genetic gain using genomic information. J. Dairy Sci. 2012;95:377-88. produced from genome edited zygotes. Sci Rep. 2013;3:2847.

404 8. Hai T, Teng F, Guo R, Li W, Zhou Q. One-step generation of knockout pigs by zygote injection of CRISPR/Cas system. Cell Res. 2014;24:372-5.

406 9. Maeder ML, Gersbach CA. Genome-editing technologies for gene and cell therapy. Mol 407 Ther. 2016;24:430-46.

408 10. Whitworth KM, Rowland RRR, Ewen CL, Trible BR, Kerrigan MA, Cino-Ozuna AG, et al. 409 Gene-edited pigs are protected from porcine reproductive and respiratory syndrome virus. Nat 410 Biotechnol. 2016;34:20-2.

411 11. Carlson DF, Lancto CA, Zang B, Kim E-S, Walton M, Oldeschulte D, et al. Production of 412 hornless dairy cattle from genome-edited cell lines. Nat Biotechnol. 2016;34:479-81.

413 12. Jenko J, Gorjanc G, Cleveland MA, Varshney RK, Whitelaw C, Woolliams JA, et al.

414 Potential of promotion of alleles by genome editing to improve quantitative traits in livestock

415 breeding programs. Genet Sel Evol. 2016;47:55.

416 13. Hickey JM, Bruce C, Whitelaw A, Gorjanc G. Promotion of alleles by genome editing in 417 livestock breeding programmes. J Anim Breed Genet. 2016;133:83-4.

418 14. Cole JB. Python programs and notebooks used for simulation of gene editing in dairy cattle 419 breeding programs. https://github.com/wintermind/gene-editing/. Accessed 13 Mar 2017.

420 15. VanRaden PM, Cole JB. AIP Research Report NM\$5 (10-14): Net merit as a measure of 421 lifetime profit: 2014 revision. In: Animal Improvement Program. Animal Genomics and 
422 Improvement Laboratory, ARS, USDA. 2014. https://aipl.arsusda.gov/reference/nmcalc-

$423 \quad 2014 . h t m$. Accessed 23 Feb 2017.

424 16. Van Doormaal BJ, Kistemaker GJ. 2008. Managing genetic recessives in Canadian

425 Holsteins. Interbull Bull. 2008;38:75-9.

426 17. Falconer DS, MacKay TFC. Introduction to quantitative genetics. London: Longman; 1996.

427 18. Seabold JS, Perktold J. Statsmodels. Econometric and statistical modeling with Python. In

428 Proceedings of the 9th Python in Science Conference: 28 June-3 July 2010; Austin, TX.

429 http://conference.scipy.org/proceedings/scipy2010/pdfs/seabold.pdf. Accessed 7 Mar 2017.

430 19. Statsmodels. http://statsmodels.sourceforge.net/. Accessed 8 Mar 2017.

431 20. Hunter JD. Matplotlib: a 2D graphics environment. Comput Sci Eng. 2007;9:90-5.

432 21. Matpotlib. http://matplotlib.org/. Accessed 8 Mar 2017.

433 22. Seaborn: statistical data visualization. http://seaborn.pydata.org/. Accessed 8 Mar 2017.

434 23. de Sousa RV, da Silva Cardoso CR, Butzke G, Dode MAN, Rumpf R, Franco MM. Biopsy

435 of bovine embryos produced in vivo and in vitro does not affect pregnancy rates.

436 Theriogenology. 2017;90:25-31.

437 24. Faber DC, Ferre LB, Metzger J, Robl JM, Kasinathan P. Review: Agro-economic impact of

438 cattle cloning. Cloning Stem Cells. 2004;6:198-207.

43925 . Hasler JF. Forty years of embryo transfer in cattle: a review focusing on the journal

440 Theriogenology, the growth of the industry in North America, and personal reminisces.

441 Theriogenology. 2014;81:152-69.

442 26. Segelke D, Täubert H, Reinhardt F, Thaller G. Considering genetic characteristics in German

443 Holstein breeding programs. J Dairy Sci. 2016;99:458-67.

444 27. McClure MC, Bickhart D, Null D, VanRaden P, Xu L, Wiggans G, et al. 2014. Bovine 
445

446

447

448

449

450

451

452

453

454

455

456

457 strategies and lessons. J Anim Sci. 2004;82:E313-28.

458 33. Prayaga KC. Genetic options to replace dehorning in beef cattle — a review. Aust J Agric

459 Res. 2007;58:1-8.

460

461

462 for quantitative and Mendelian traits. Genet Sel Evol. 2;48:50.

463 35. Sun C, VanRaden PM. Increasing long-term response by selecting for favorable minor

464 alleles. PLoS ONE 2014;9:e88510.

465

466

467
34. Scheper C, Wensch-Dorendorf M, Yin T, Dressel H, Swalve H, König S. Evaluation of breeding strategies for polledness in dairy cattle using a newly developed simulation framework 36. Medugorac I, Seichter D, Graf A, Russ I, Blum H, Göpel KH, et al. Bovine polledness - an autosomal dominant trait with allelic heterogeneity. PLoS One 2012;7:e39477.

37. Rothammer S, Capitan A, Mullaart E, Seichter D, Russ I, Medugorac I. The 80-kb DNA 
468 duplication on BTA1 is the only remaining candidate mutation for the polled phenotype of

$469 \quad$ Friesian origin. Genet Sel Evol. 2014;46:44.

470 38. Ledford H. Transgenic salmon leaps to the dinner table. Nature. 2015;527:417-8.

471 39. Waltz E. Gene-edited CRISPR mushroom escapes US regulation. Nature. 2016;532:293.

472 40. Maxmen A. Gene-edited animals face US regulatory crackdown. Nature. 2017;

473 doi:10.1038/nature.2017.21331.

474 41. Large Animal Genetic Engineering Summit. http://lage.usu.edu/. Accessed 10 Mar 2017.

475 42. Whitelaw CBA, Sheets TP, Lillico SG, Telugu BP. Engineering large animal models of

476 human disease. J Pathol. 2016;238:247-56.

477 43. Carroll D, Van Eenennaam AL, Taylor JF, Seger J, Voytas DF. Regulate genome-edited

478 products, not genome editing itself. Nat Biotechnol. 2016;34:477-9.

479 44. Thompson NM, Widmar NO, Schutz MM, Cole JB, Wolf CA. Economic and social

480 considerations of breeding for polled dairy cows versus dehorning. J Dairy Sci. 2017;100:in

481 press.

482 45. Plastow GS. Genomics to benefit livestock production: improving animal health. Rev Bras 483 Zootec. 2016;45:349-54.

484 46. Burkard C, Lillico SG, Reid E, Jackson B, Mileham, AJ, Ait-Ali T, et al. Precision

485 engineering for PRRSV resistance in pigs: Macrophages from genome edited pigs lacking

486 CD163 SRCR5 domain are fully resistant to both PRRSV genotypes while maintaining

487 biological function. PLoS Pathogens 2017;13:e1006206.

488 47. Gao Y, Wu H, Wang Y, Liu X, Chen L, Li Q, et al. Single Cas9 nickase induced generation

489 of NRAMP1 knockin cattle with reduced off-target effects. Genome Biol. 2017;18:13.

490 48. Caroli AM, Chessa S, Erhardt GJ. Invited review: Milk protein polymorphisms in cattle: 
491 Effect on animal breeding and human nutrition. J Dairy Sci. 2009;92:5335-5352.

492 49. Dikmen S, Alava E, Pontes E, Fear JM, Dikmen BY, Olson TA, et al. Differences in

493 thermoregulatory ability between slick-haired and wild-type lactating Holstein cows in response

494 to acute heat stress. J Dairy Sci. 2008;91:3395-3402.

495 50. Grisart B, Coppieters W, Farnir F, Karim L, Ford C, Berzi P, et al. Positional candidate

496 cloning of a QTL in dairy cattle: identification of a missense mutation in the bovine DGAT1

497 gene with major effect on milk yield and composition. Genome Res. 2002;12:222-231.

498 51. Tizard M, Hallerman E, Fahrenkrug S, Newell-McGloughlin M, Gibson J, de Loos F, et al.

499 Strategies to enable the adoption of animal biotechnology to sustainably improve global food

500 safety and security. Transgenic Res. 2016;25:575-95.

501 52. Zhang C, Wohlhueter R, Zhang H. Genetically modified foods: a critical review of their

502 promise and problems. Food Sci. Hum. Wellness 2016;5:116-23.

503 53. Hess S, Lagerkvist CJ, Redekop W, Pakseresht A. Consumers' evaluation of

504 biotechnologically modified food products: new evidence from a meta-survey. Eur Rev Agric

505 Econ. 2016;43:703-36.

506 54. Mather D, Vikan R, Knight J. Marketplace response to GM animal products. Nat.

507 Biotechnol. 2016;34:236-8.

508 55. Ishii T, Araki M. Consumer acceptance of food crops developed by genome editing. Plant

509 Cell Rep. 2016;35:1507-18. doi:10.1007/s00299-016-1974-2.

510 56. Ragan-Kelley M, Perez F, Granger B, Kluyver T, Ivanov P, Frederic J, et al. 2014. The

511 Jupyter/IPython architecture: a unified view of computational research, from interactive

512 exploration to communication and publication. Abstr H44D-07 presented at 2014 Fall Meeting,

513 AGU, San Francisco, CA, 15-19 Dec. http://abstractsearch.agu.org/meetings/2014/FM/H44D- 
bioRxiv preprint doi: https://doi.org/10.1101/116459; this version posted March 14, 2017. The copyright holder for this preprint (which was not certified by peer review) is the author/funder, who has granted bioRxiv a license to display the preprint in perpetuity. It is made available under aCC-BY 4.0 International license.

$514 \quad$ 07.html. Accessed 10 Mar 2017. 


\section{Figures}

Figure 1 Flowchart for gene editing and embryo transfer in the simulation

Figure 2 Schematic of simulated scenarios

Terms are nested within one another from left to right (e.g., the proportion of bulls edited is nested within the recessive scenario). CRISPR clustered regularly interspaced short palindromic repeats, TALEN transcription activator-like effector nuclease, Perfect $=$ hypothetical technology with a perfect success rate, $Z F N$ zinc finger nuclease

Figure 3 Observed minor allele frequency of the Holstein recessive locus $\mathrm{HH} 3$ for five different gene-editing technologies over 20 years

a Top $1 \%$ of bulls and $0 \%$ of cows were edited. b Top $10 \%$ of bulls and top $1 \%$ of cows were edited. CRISPR clustered regularly interspaced short palindromic repeats, TALEN transcription activator-like effector nuclease, Perfect $=$ hypothetical technology with a perfect success rate, $Z F N$ zinc finger nuclease

Figure 4 Observed versus expected changes in allele frequencies of the Holstein recessive locus HH3 for five different gene-editing technologies over 20 years

a Top $1 \%$ of bulls and $0 \%$ of cows were edited. b Top $10 \%$ of bulls and top $1 \%$ of cows were edited. CRISPR clustered regularly interspaced short palindromic repeats, TALEN transcription activator-like effector nuclease, Perfect $=$ hypothetical technology with a perfect success rate, ZFN zinc finger nuclease

Figure 5 Average inbreeding rate in a simulation of 12 Holstein recessive loci for five different gene-editing technologies over 20 years

a Top $1 \%$ of bulls and $0 \%$ of cows were edited. b Top $10 \%$ of bulls and top $1 \%$ of cows were edited. CRISPR clustered regularly interspaced short palindromic repeats, TALEN transcription activator-like effector nuclease, Perfect $=$ hypothetical technology with a perfect success rate, $Z F N$ zinc finger nuclease

Figure 6 Observed minor allele frequency of the Holstein recessive locus horned for five different gene-editing technologies over 20 years

a Top $1 \%$ of bulls and $0 \%$ of cows were edited. b Top $10 \%$ of bulls and top $1 \%$ of cows were edited. CRISPR clustered regularly interspaced short palindromic repeats, TALEN transcription activator-like effector nuclease, Perfect $=$ hypothetical technology with a perfect success rate, $Z F N$ zinc finger nuclease 
Figure 7 Observed versus expected changes in allele frequencies of the Holstein recessive locus horned for five different gene-editing technologies over 20 years

a Top $1 \%$ of bulls and $0 \%$ of cows were edited. b Top $10 \%$ of bulls and top $1 \%$ of cows were edited. CRISPR clustered regularly interspaced short palindromic repeats, TALEN transcription activator-like effector nuclease, Perfect $=$ hypothetical technology with a perfect success rate, $Z F N$ zinc finger nuclease

Figure 8 Proportion of embryos that died each year because of the effects of recessive genotypes for five different gene-editing technologies over 20 years

a Top $1 \%$ of bulls and $0 \%$ of cows were edited. b Top $10 \%$ of bulls and top $1 \%$ of cows were edited. CRISPR clustered regularly interspaced short palindromic repeats, TALEN transcription activator-like effector nuclease, Perfect $=$ hypothetical technology with a perfect success rate, ZFN zinc finger nuclease

Figure 9 Proportions of genotyped Holsteins that have known recessives by animal sex

Bulls and cows were born from 2000 through 2015. Carrier status was either not a carrier of a known recessive or a carrier of one known recessive or more. 
Figure 1 Flowchart for gene editing and embryo transfer in the simulation

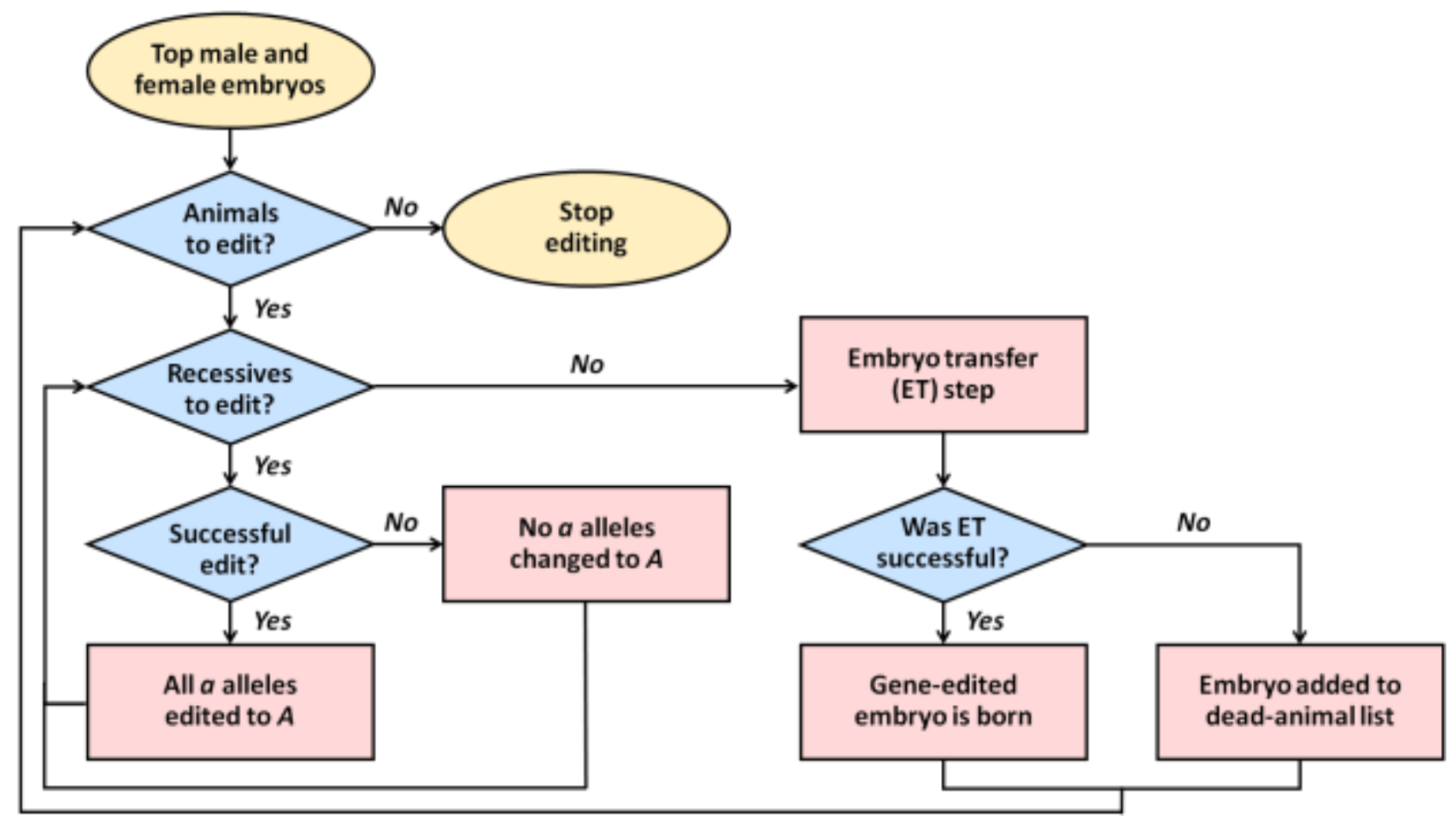




\section{Figure 2 Schematic of simulated scenarios}

Terms are nested within one another from left to right (e.g., the proportion of bulls edited is nested within the recessive scenario). CRISPR clustered regularly interspaced short palindromic repeats, TALEN transcription activator-like effector nuclease, Perfect $=$ hypothetical technology with a perfect success rate, $Z F N$ zinc finger nuclease

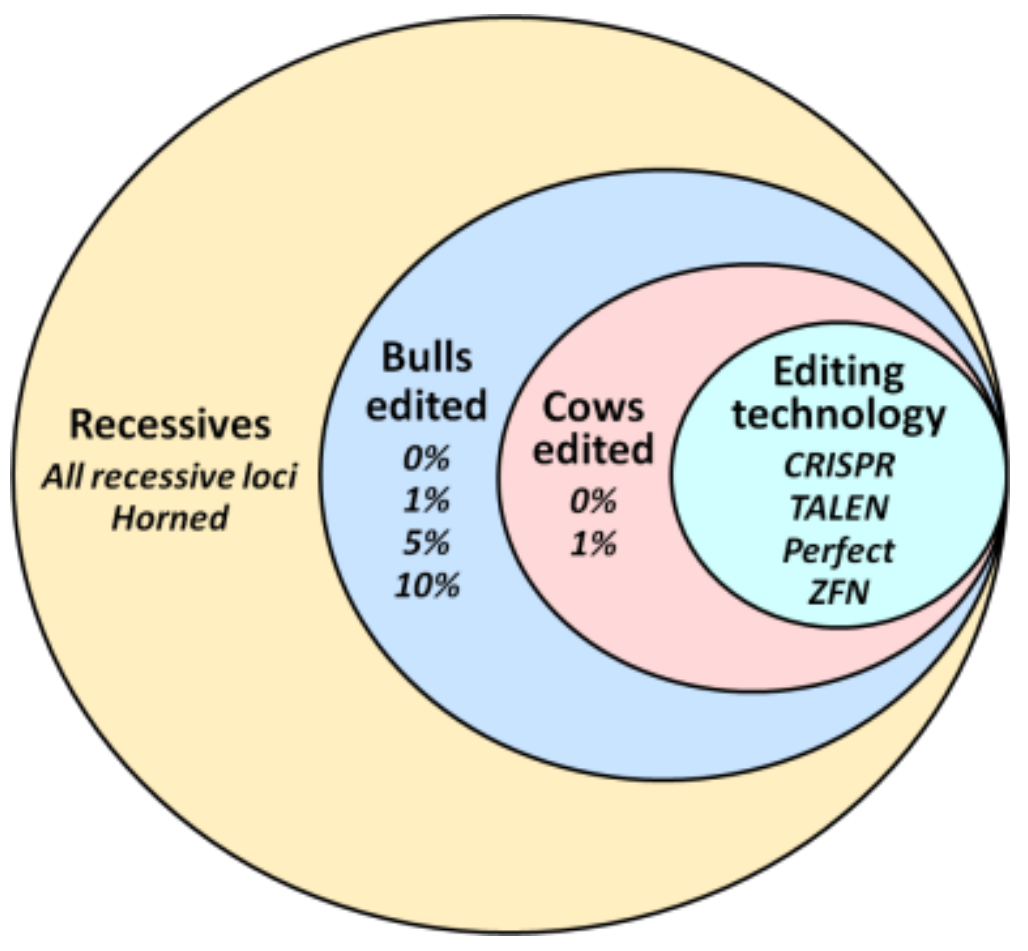


Figure 3 Observed minor allele frequency of Holstein recessive locus $\mathrm{HH} 3$ for five different gene-editing technologies over 20 years

a Top $1 \%$ of bulls and $0 \%$ of cows were edited. b Top $10 \%$ of bulls and top $1 \%$ of cows were edited. CRISPR clustered regularly interspaced short palindromic repeats, TALEN transcription activator-like effector nuclease, Perfect $=$ hypothetical technology with a perfect success rate, $Z F N$ zinc finger nuclease

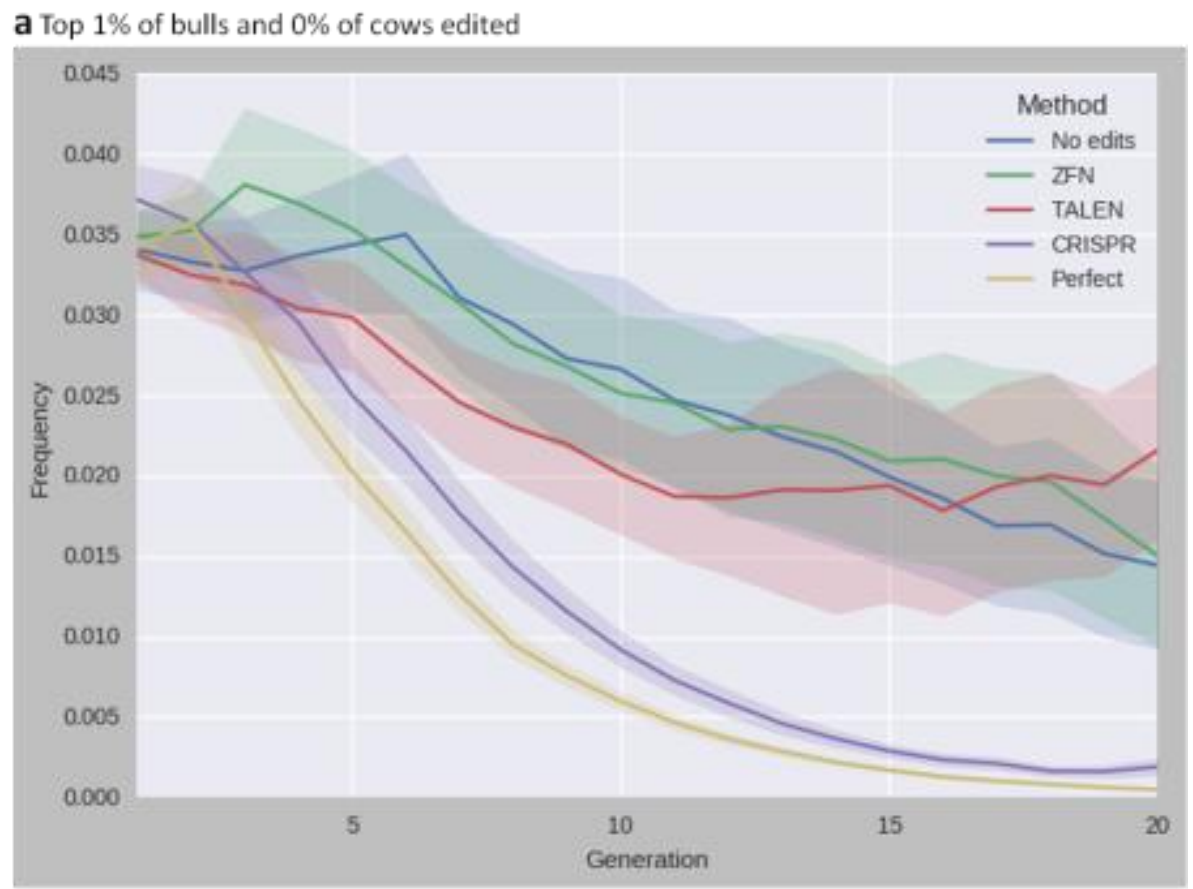

b Top $10 \%$ of bulls and top $1 \%$ of cows edited

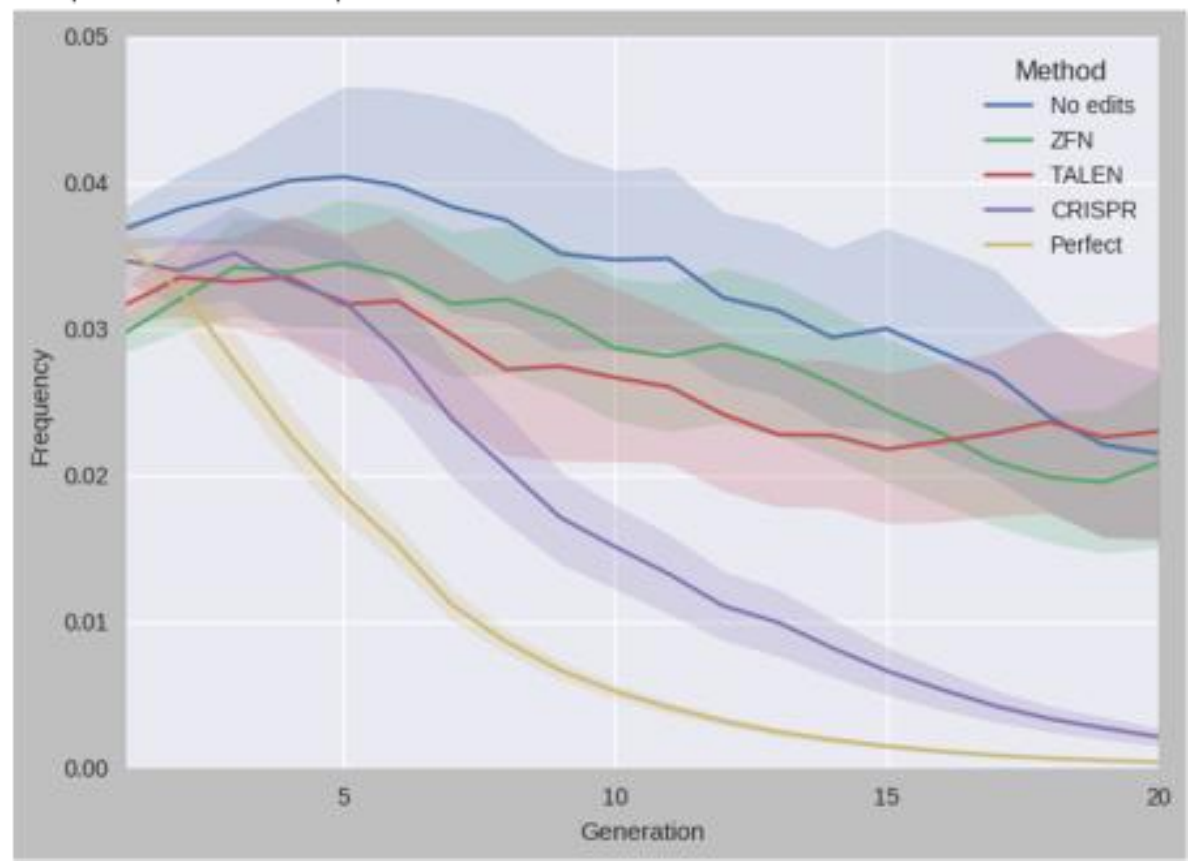


Figure 4 Observed versus expected changes in allele frequencies of Holstein recessive locus HH3 for five different gene-editing technologies over 20 years

a Top $1 \%$ of bulls and $0 \%$ of cows were edited. b Top $10 \%$ of bulls and top $1 \%$ of cows were edited. CRISPR clustered regularly interspaced short palindromic repeats, TALEN transcription activator-like effector nuclease, Perfect $=$ hypothetical technology with a perfect success rate, ZFN zinc finger nuclease

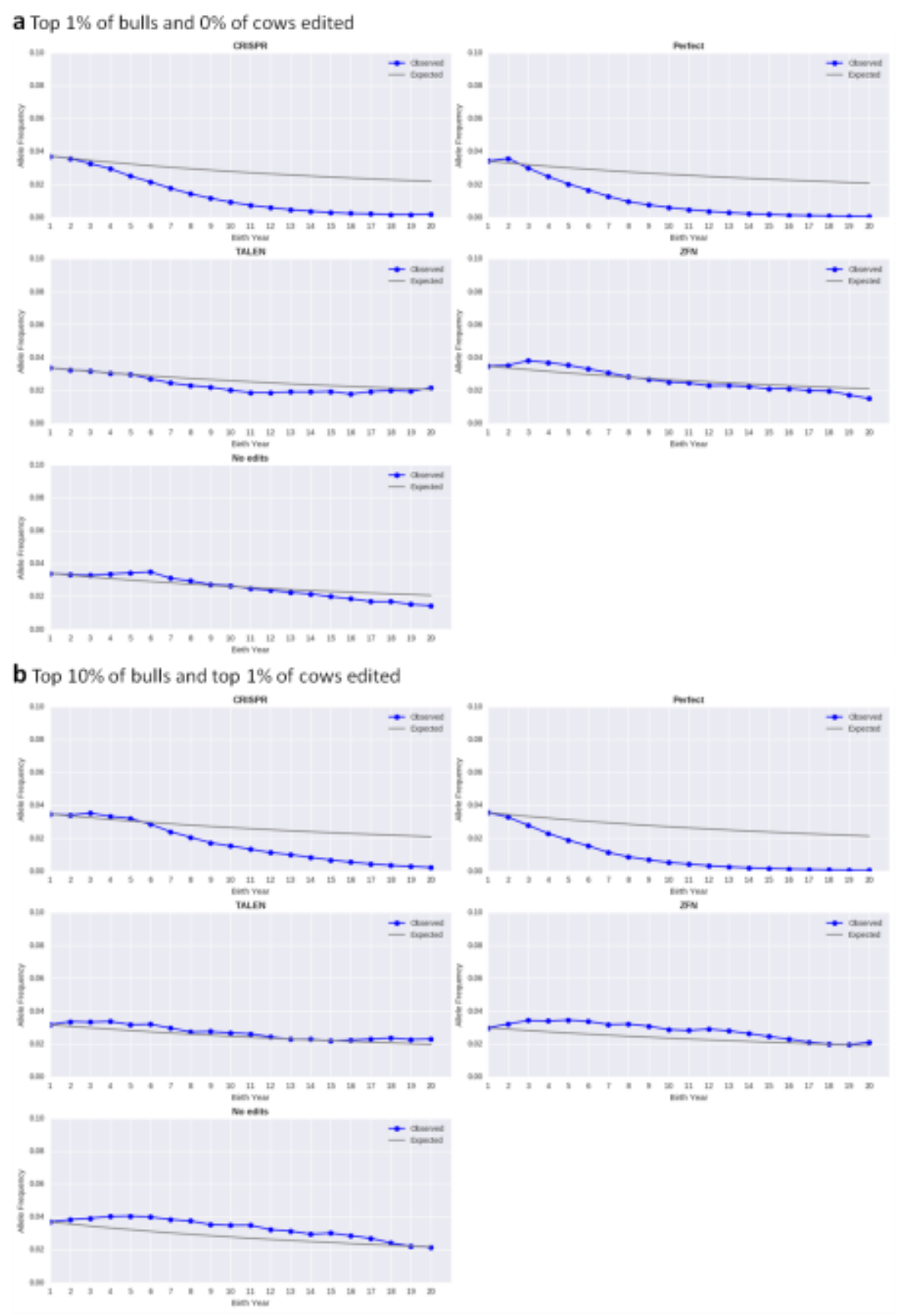




\section{Figure 5 Average inbreeding rate in a simulation of 12 Holstein recessive loci for five different gene-editing technologies over 20 years}

a Top $1 \%$ of bulls and $0 \%$ of cows were edited. b Top $10 \%$ of bulls and top $1 \%$ of cows were edited. CRISPR clustered regularly interspaced short palindromic repeats, TALEN transcription activator-like effector nuclease, Perfect $=$ hypothetical technology with a perfect success rate, $Z F N$ zinc finger nuclease

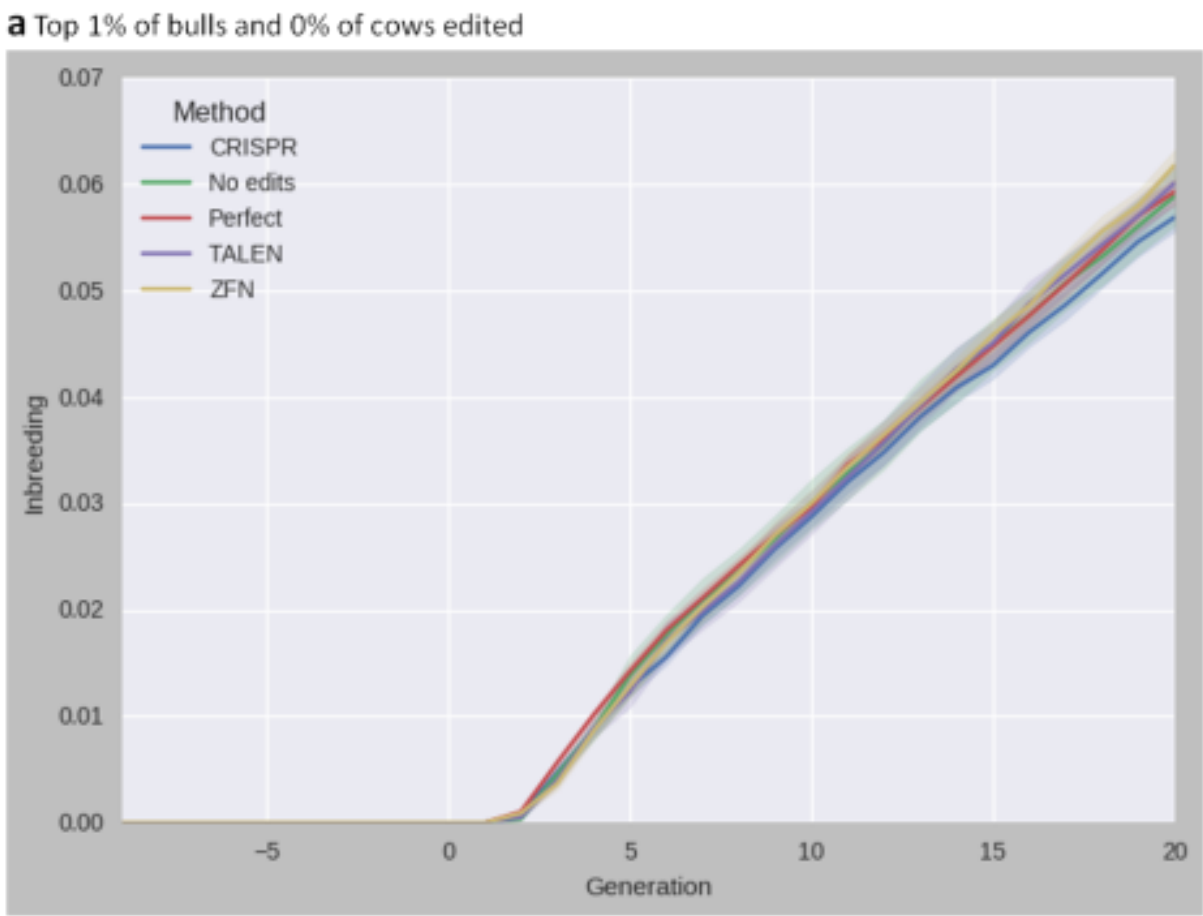

b Top $10 \%$ of bulls and top $1 \%$ of cows edited

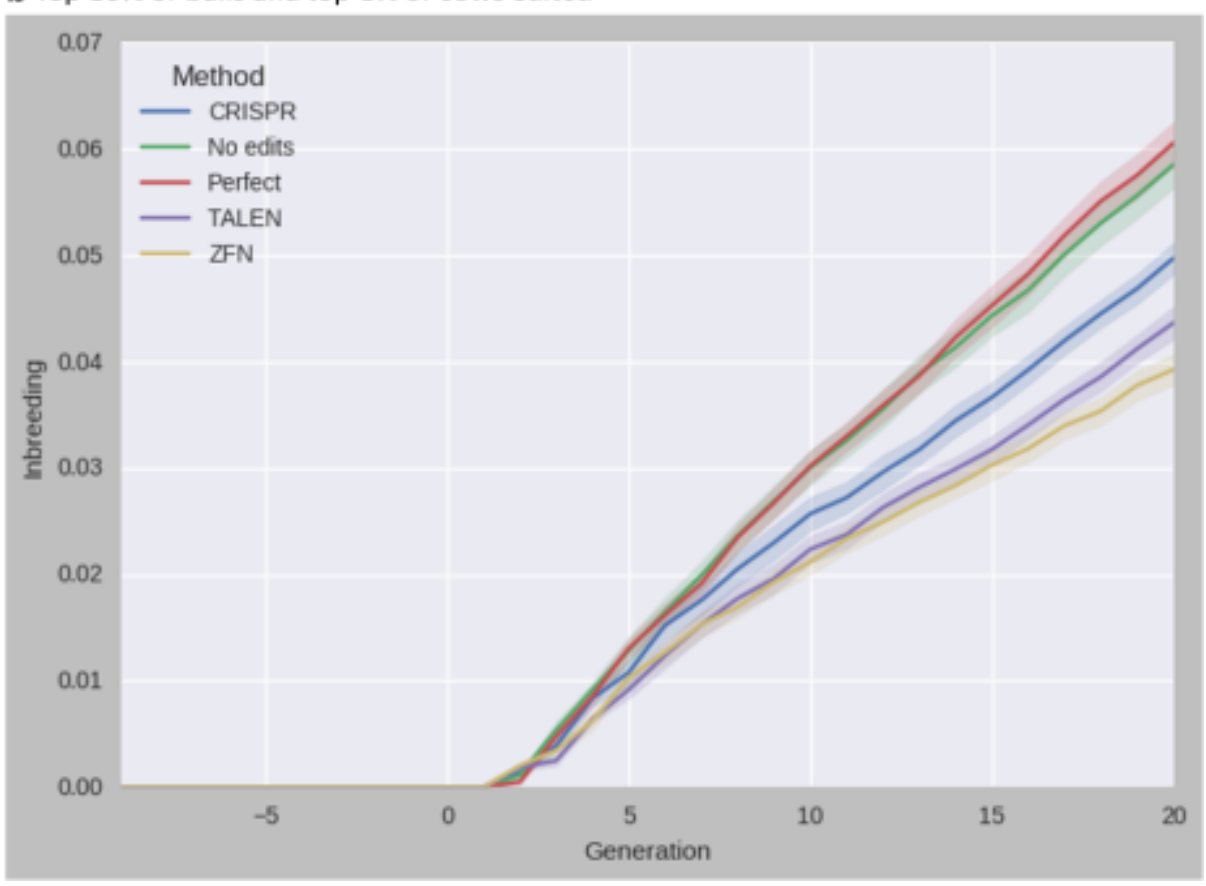


Figure 6 Observed minor allele frequency of the Holstein recessive locus horned for five different gene-editing technologies over 20 years

a Top $1 \%$ of bulls and $0 \%$ of cows were edited. b Top $10 \%$ of bulls and top $1 \%$ of cows were edited. CRISPR clustered regularly interspaced short palindromic repeats, TALEN transcription activator-like effector nuclease, Perfect $=$ hypothetical technology with a perfect success rate, ZFN zinc finger nuclease

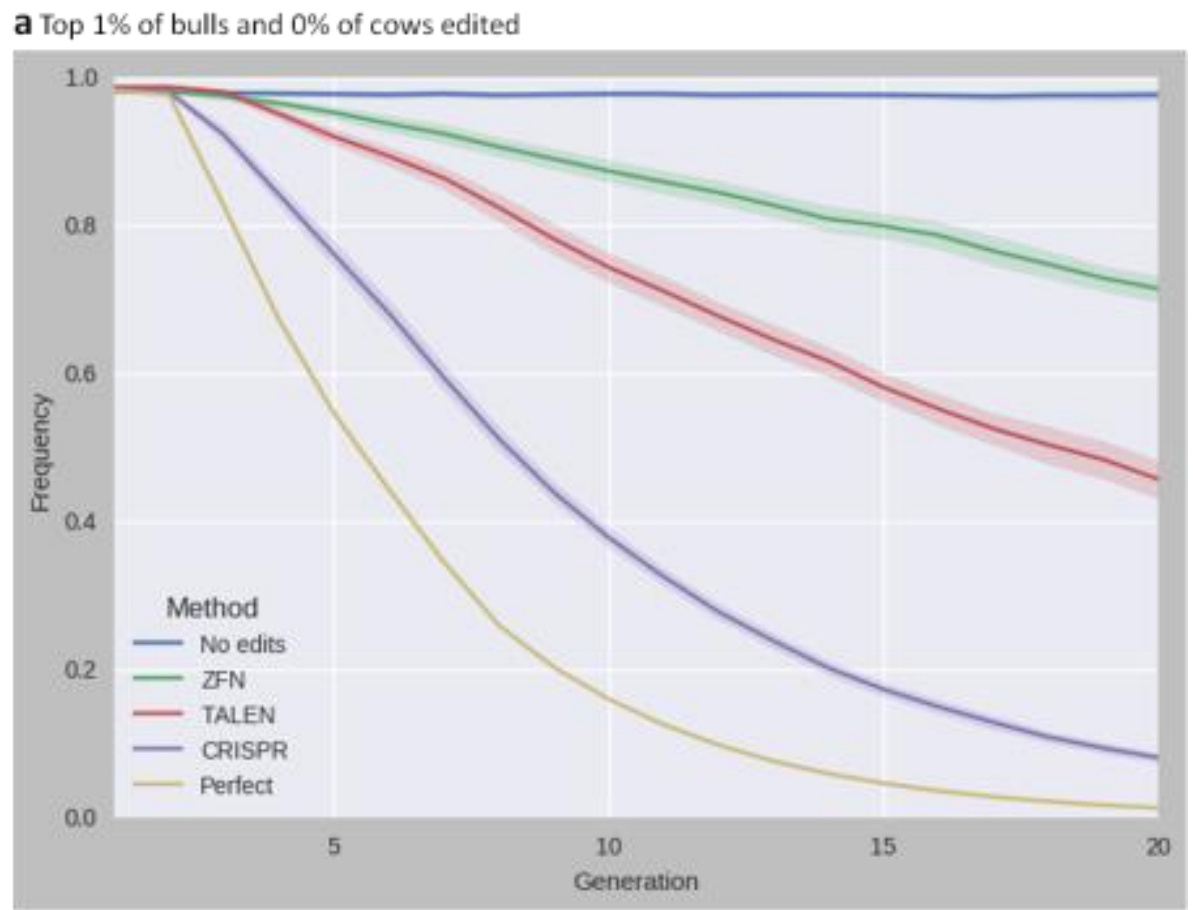

b Top $10 \%$ of bulls and top $1 \%$ of cows edited

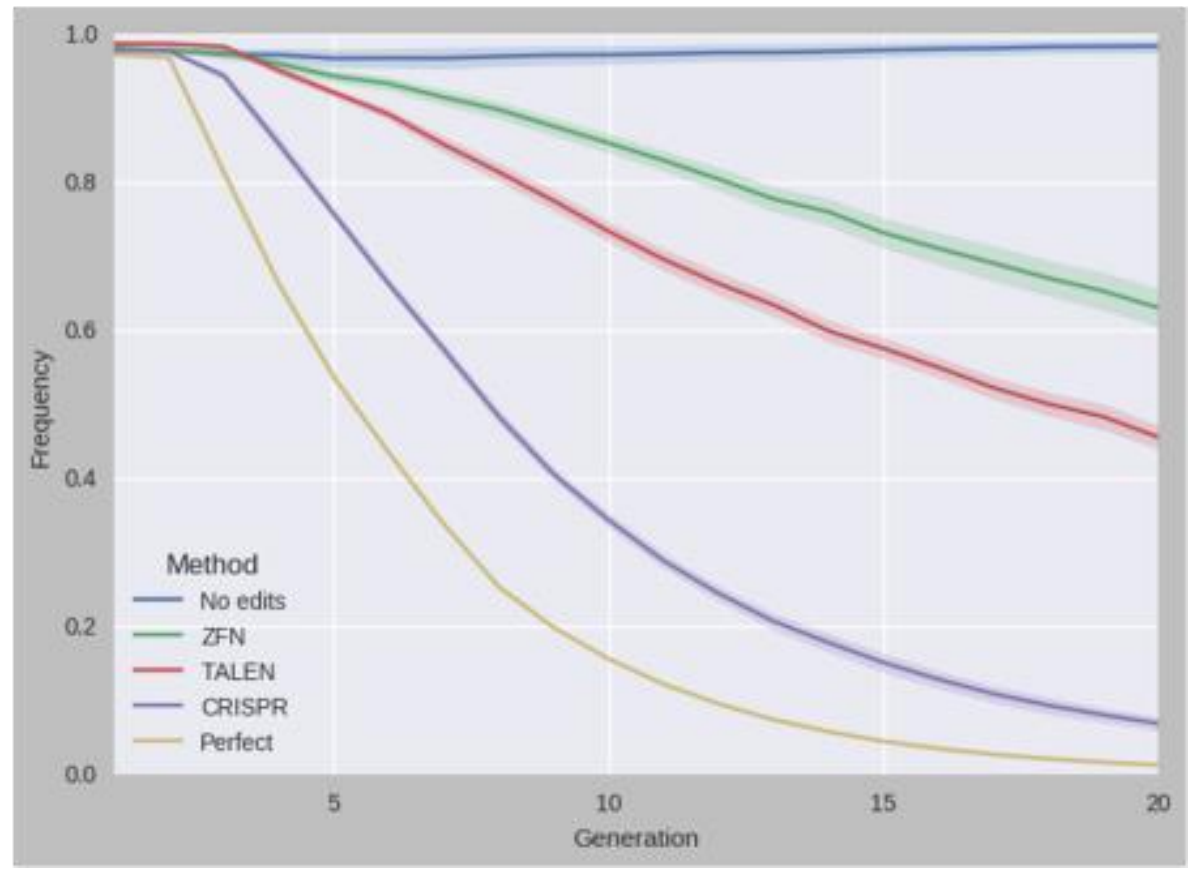


Figure 7 Observed versus expected changes in allele frequencies of the Holstein recessive locus horned for five different gene-editing technologies over 20 years

a Top $1 \%$ of bulls and $0 \%$ of cows were edited. b Top $10 \%$ of bulls and top $1 \%$ of cows were edited. CRISPR clustered regularly interspaced short palindromic repeats, TALEN transcription activator-like effector nuclease, Perfect $=$ hypothetical technology with a perfect success rate, ZFN zinc finger nuclease

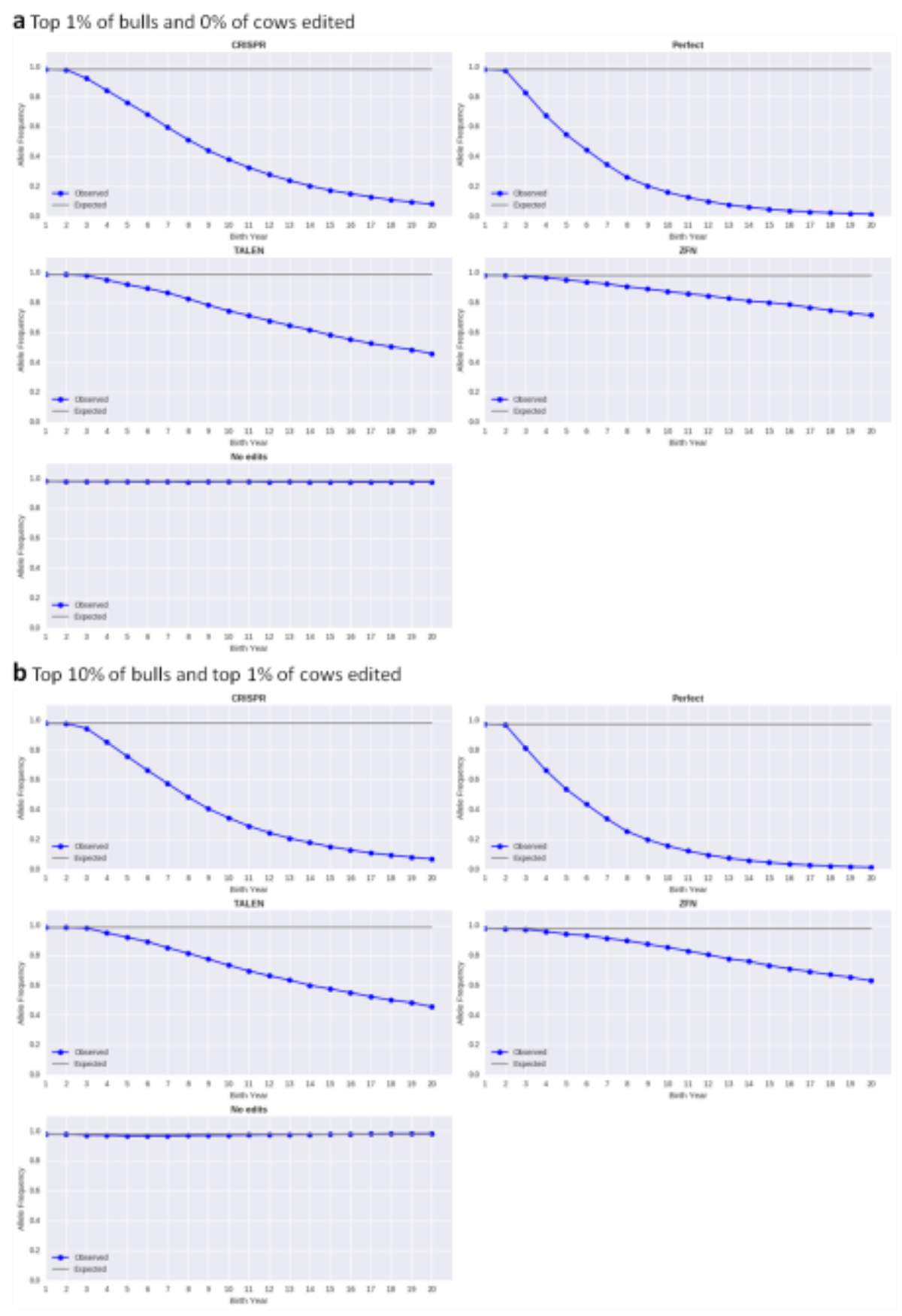


Figure 8 Proportion of embryos that died each year because of the effects of recessive genotypes for five different gene-editing technologies over 20 years

a Top $1 \%$ of bulls and $0 \%$ of cows were edited. b Top $10 \%$ of bulls and top $1 \%$ of cows were edited. CRISPR clustered regularly interspaced short palindromic repeats, TALEN transcription activator-like effector nuclease, Perfect $=$ hypothetical technology with a perfect success rate, ZFN zinc finger nuclease

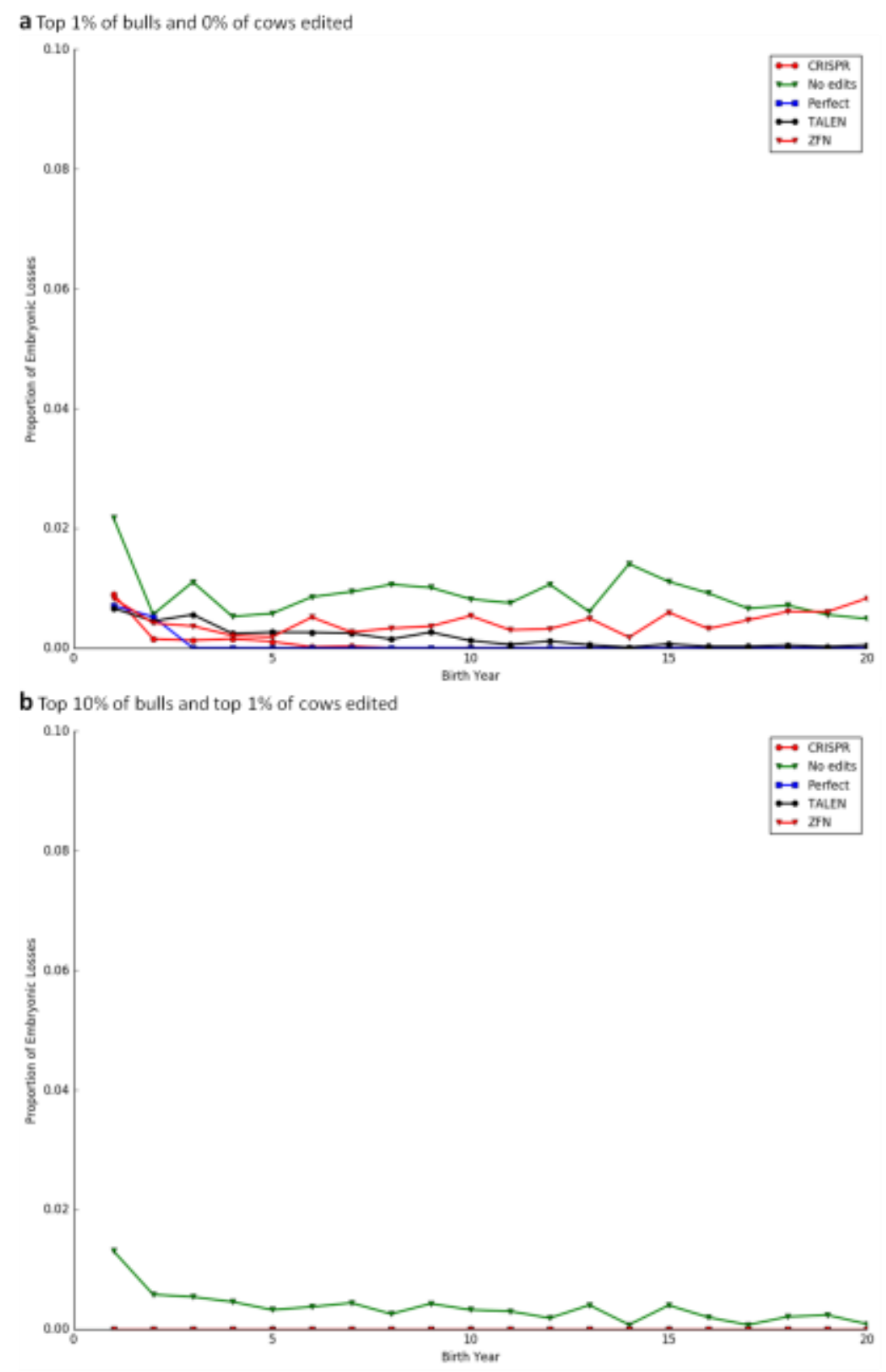


bioRxiv preprint doi: https://doi.org/10.1101/116459; this version posted March 14, 2017. The copyright holder for this preprint (which was not certified by peer review) is the author/funder, who has granted bioRxiv a license to display the preprint in perpetuity. It is made available under aCC-BY 4.0 International license.

\section{Figure 9 Proportions of genotyped Holsteins that have known recessives by birth year}

Bulls and cows were born from 2000 through 2015. Carrier status was either not a carrier of a known recessive or a carrier of one known recessive or more.

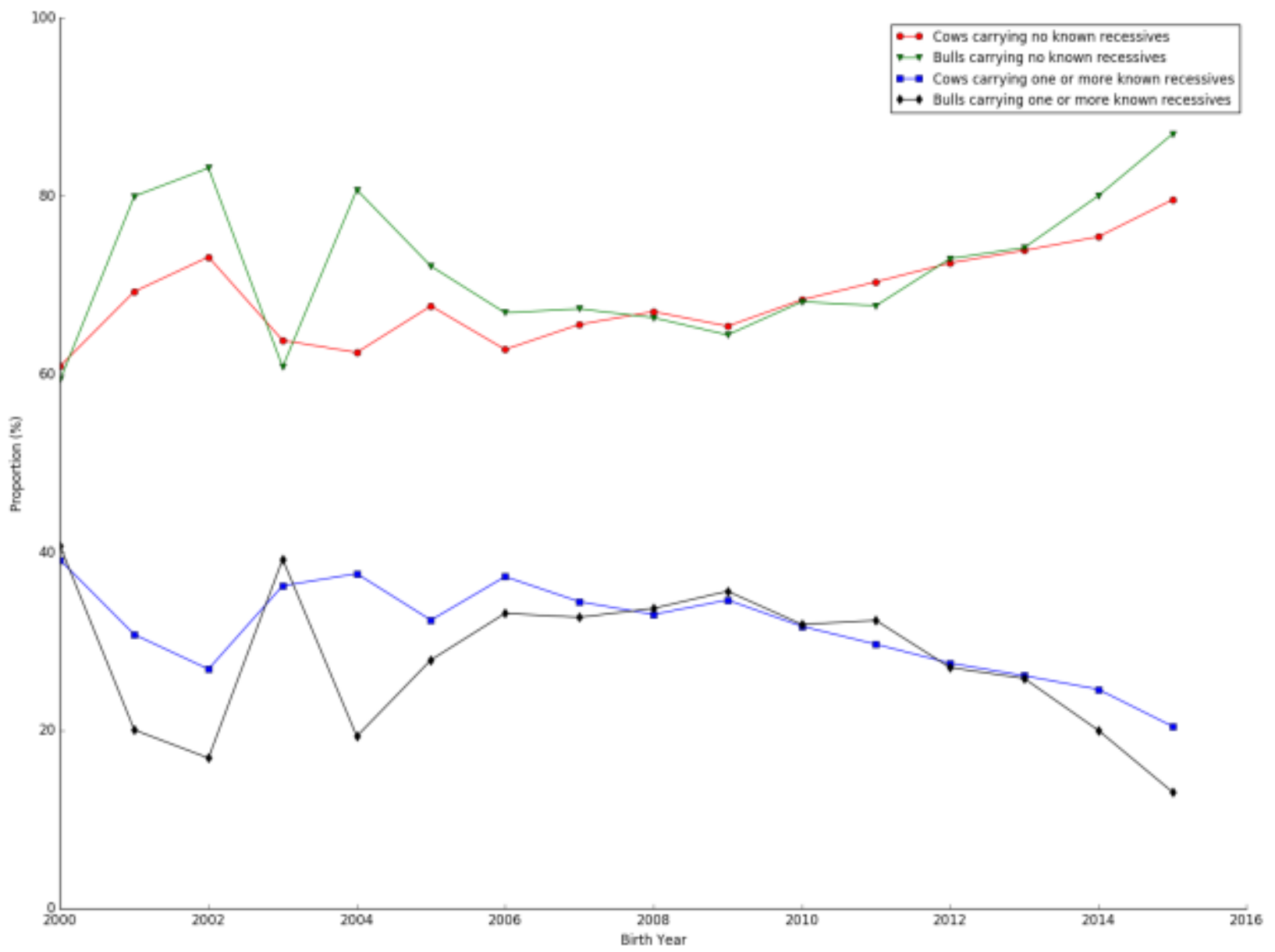

